\title{
Do Spanish patients drink alcohol while undergoing treatment with benzodiazepines?
}

\author{
M. Carmen Del Río, Carlos Prada, F. Javier Alvarez* \\ Drugs and Alcohol Research Group, Department of Pharmacology and Therapeutics, Faculty of Medicine, University of Valladolid, 47005 Valladolid, Spain
}

Received 27 April 2001; received in revised form 1 August 2001; accepted 6 September 2001

\begin{abstract}
In this study, we analyzed patterns of combined benzodiazepines and alcohol use among the Spanish general population over the age of 16 years. The study was based on information from the 1997 Spanish National Household Health Survey. A total of 6,396 persons over 16 years of age, a representative sample of noninstitutionalized Spaniards, were surveyed. One percent of the population are consumers of benzodiazepines and daily drinkers of alcohol; fundamentally, these consumers are men, of whom $15.4 \%$ drink alcohol at a high level ( $>50$ units/week). Findings show the frequency of concurrent use of benzodiazepines and alcohol by the Spanish population. (C) 2002 Elsevier Science Inc. All rights reserved.
\end{abstract}

Keywords: Alcohol-drug interaction; Alcohol; Benzodiazepines; Drug utilization

\section{Introduction}

Benzodiazepines are widely prescribed because of both their effectiveness and their safety in the treatment of multiple psychiatric and physical diseases. But, despite their being safe drugs, one of the greatest risks is that adverse effects may be produced when taking benzodiazepines owing to their interaction with other substances - particularly with psychoactive medication and alcohol. Adverse drug interactions are an important clinical problem, and it is well known that several different mechanisms are implicated in their pathogenesis. In regard to benzodiazepines, alcohol interferes both at the pharmacokinetic and at the pharmacodynamic level, which means that the occurrence of adverse effects is more frequent (Harris et al., 1998; Tanaka \& Misawa, 1998).

Benzodiazepines are widely taken in Spain, more commonly by women and the elderly (Del Río \& Alvarez, 1996; Rayón et al., 1996). Additionally, the taking of hypnotic and anxiolytic benzodiazepines has increased considerably in the past 10 years, compared with the decrease in consumption in other Western countries, such as the Nordic countries, the United Kingdom, and the United States (Rayón

\footnotetext{
* Corresponding author. Tel.: +34-983-423077; fax: +34-983-423022.

E-mail address: alvarez@med.uva.es (F.J. Alvarez).

Editor: S. Borg
}

et al., 1996; Tiller, 1994). Moreover, in Spain, drinking alcohol is a social habit, and there are many who drink regularly (Del Río et al., 1995).

Information relating to the use of benzodiazepines and alcohol together is scant, and the aim of this study was to analyze patterns of combined benzodiazepines and alcohol use among the Spaniards.

\section{Methods}

The study was based on information from the 1997 Spanish National Household Health Survey, undertaken by the Ministry of Health and Consumption (Ministerio de Sanidad y Consumo, 2000) to obtain data on aspects relating to health and the use of health resources. The procedures followed were in accordance with the ethical standards of the committee responsible for human experimentation (the Ethics Committee of the Faculty of Medicine) and with the Helsinki Declaration of 1975, as revised in 1983.

A survey of 6,396 persons over 16 years of age, a representative sample of noninstitutionalized Spaniards, was carried out. The sample was stratified: first, by Spanish communities; second, in seven stages, by number of inhabitants; third, by cities in each of the communities; and, finally, by sex (3,102 males, 3,294 females) and age (in 
years) $(1,353$, age $16-25 ; 1,227$, age $26-35 ; 1,012$, age $36-45 ; 853$, age $46-55 ; 927$, age $56-65 ; 673$, age $66-75$; 352, age $>75$ ).

Those surveyed were asked whether they had taken benzodiazepines in the 2-week period before the interview. In regard to alcohol, they were asked whether they had had any type of alcoholic beverage in the preceding 2 weeks and, if the answer was affirmative, how often, the number of alcoholic drinks consumed on each occasion, and the type (wine, beer, or spirits). Daily drinkers were considered to be those who spoke of having at least one drink a day. The amount of alcohol consumed was expressed in grams of absolute alcohol consumed per day, in accordance with the alcohol content of Spanish drinks and the volume of intake of each of the different drinks.

To facilitate the registration and monitoring of alcohol consumption and to provide comparable data, the use of a drink-unit system is recommended. A unit is the alcohol content in defined volumes of different beverages with a standard strength (the standard drink unit for Spain has been defined as 10 grams of pure alcohol) (Rodriguez-Martos et al., 1999). Drinkers were classified according to their consumption level: low consumption (men, $\leq 21$ units/week, and women, $\leq 14$ units/week); moderate consumption (men, 22-50 units/week, and women, 15-35 units/week); high consumption (men, $>50$ units/week, and women, $>35$ units/ week) (Del Río et al., 1995). The questionnaires were administered by trained interviewers.

Statistical analysis was undertaken with the use of SAS software version 6.07. Frequencies were compared by utilizing $\chi^{2}$ analysis. Values of $P$ less than or equal to .05 were considered to be significant differences.

\section{Results}

Of the participating adult population, $6.4 \%$ (males, $4.1 \%$; females, $\left.8.5 \% ; \chi^{2}=50.86, d f=1 ; P<.0001\right)$ had taken benzodiazepines in the 2 weeks before the survey, and use

Benzodiazepines plus alcohol $\square$ Benzodiazepines

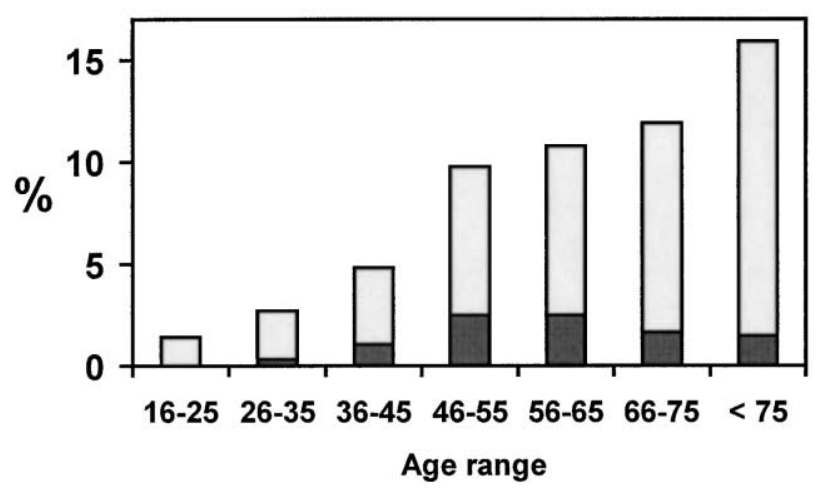

Fig. 1. Alcohol consumption among those taking benzodiazepines.
Table 1

The use of benzodiazepines and alcohol among the Spanish population

\begin{tabular}{|c|c|c|c|}
\hline & \multicolumn{3}{|l|}{ Total sample } \\
\hline & $\begin{array}{l}\text { Total } \\
(n=6396) \%\end{array}$ & $\begin{array}{l}\text { Males } \\
(n=3102) \%\end{array}$ & $\begin{array}{l}\text { Females } \\
(n=3294) \%\end{array}$ \\
\hline Take benzodiazepines & 6.4 & 4.1 & 8.5 \\
\hline Drink daily & 23.7 & 33.0 & 10.9 \\
\hline \multirow{3}{*}{$\begin{array}{l}\text { Take benzodiazepines }+ \\
\text { drink daily }\end{array}$} & 1.0 & 1.3 & 0.8 \\
\hline & \multicolumn{3}{|c|}{ Population taking benzodiazepines } \\
\hline & $\begin{array}{l}\text { Total } \\
(n=407) \%\end{array}$ & $\begin{array}{l}\text { Males } \\
(n=127) \%\end{array}$ & $\begin{array}{l}\text { Females } \\
(n=280) \%\end{array}$ \\
\hline Daily drinkers & 16 & 30.5 & 9.3 \\
\hline \multicolumn{4}{|l|}{ Consumption level } \\
\hline Low & 58.5 & 43.6 & 80.8 \\
\hline Moderate & 32.3 & 41.0 & 19.2 \\
\hline High & 9.2 & 15.4 & 0 \\
\hline
\end{tabular}

increased with increasing age: from $1.4 \%$ in the group 16-to-25 years of age to $15.9 \%$ in the group older than 75 years of age (Fig. 1). In addition, 23.7\% (males, 33\%; females, $\left.10.9 \% ; \chi^{2}=613.99, d f=1 ; P<.0001\right)$ of the population drank alcohol on a daily basis.

When use of benzodiazepines and consumption of alcohol were analyzed jointly, $16 \%$ were seen to be daily drinkers ( $1 \%$ of all those surveyed), more commonly among men $(30.5 \%)$ than among women $\left(9.3 \% ; \chi^{2}=29.25, d f=1\right.$; $P<.0001)$ (Table 1). Consumption increased with increasing age of the population, from $0 \%$ in the 16 -to- 25 years age group to $12.1 \%$ in the $26-35$ years age group to a maximum of $23 \%$ in the 56-to- 65 years age group, after which it went down (Fig. 1). Mean alcohol consumption among those taking benzodiazepines and drinking daily was $35.99 \pm 28.67 \mathrm{~g} /$ day: $44.28 \pm 44.22 \mathrm{~g} /$ day for men and $17.65 \pm 9.19 \mathrm{~g}$ /day for women. In terms of benzodiazepine use and daily alcohol consumption, $58.5 \%$ drank at a low level, 32.3\% drank at a moderate level, and 9.2\% drank at a high level. Differences according to sex also were evident $\left(\chi^{2}=9.98, d f=2, P<.01\right)$; women drank alcohol at a low level $(80.8 \%)$ more often than men $(43.6 \%)$, whereas men consumed alcohol at moderate $(41.0 \%)$ and high $(15.4 \%)$ levels more frequently than women $(19.2 \%$ and $0 \%$, respectively) (Table 1 ).

There were more daily consumers of alcohol (24.2\%) among those not taking benzodiazepines than among those taking them $\left(16 \%, \chi^{2}=14.31, d f=1, P<.0001\right)$. Nevertheless, the distribution of drinkers according to their level of consumption did not differ, either among those who took benzodiazepines or those who did not take them $\left(\chi^{2}=1.73, d f=2, P>.05\right)$.

\section{Discussion}

According to our study results, $6.4 \%$ of the Spanish population take benzodiazepines, especially females and 
the elderly. In addition, $1 \%$ of the population are consumers of benzodiazepines and daily drinkers of alcohol; fundamentally, they are men, of whom $15.4 \%$ drink alcohol at a high level (>50 units/week). Our findings also indicate that alcohol consumption is more common among people not taking benzodiazepines than among those who do take them.

In our study, we observed a lower rate of benzodiazepine use than that in other, nearby countries, such as Finland (Joukamaa et al., 1995), Italy (Magrini et al., 1996), and the Netherlands (van der Waals et al., 1993; van Hulten et al., 1998), but a clearly higher rate than that of the United Kingdom (Ohayon et al., 1998) and the United States (Simon et al., 1996), although differences among different types of populations have to be taken into consideration. With regard to alcohol consumption among those who take benzodiazepines, $15.4 \%$ consume alcohol at a high level. In other studies, a high rate of alcohol dependence was found among those who take high doses of benzodiazepines (Lekka et al., 1997).

In the present study, benzodiazepines were more frequently used by women than by men, as previously reported (Magrini et al., 1996; Rayón et al., 1996; van Hulten et al., 1998). In addition, benzodiazepine use together with alcohol consumption were analyzed. Men took benzodiazepines with alcohol more frequently than did women, as observed in previous studies, which correlates with the fact that alcohol consumption is more common among men than women (Del Río et al., 1995).

Pharmacokinetic and pharmacodynamic interactions between alcohol and benzodiazepines can have significant clinical implications, such as the impairment of many motor, sensory, and neurological functions, with a greater risk of sedation and, consequently, a greater risk of accidents, including road, work, and possible sudden death (Barbone et al., 1998; Neutel, 1998; Tanaka \& Misawa, 1998). These side effects can impair the quality of life and have led to a critical discussion about the practice of prescribing benzodiazepines and the information provided by physicians (Gutierrez-Lobos et al., 2001). Our findings do not permit us to establish whether interactions take place between benzodiazepines and alcohol but allow us to presume that they did in some cases. To prevent drug-ethanol interactions, physicians should pay more attention to this possible occurrence (Del Río et al., 1996).

European Union regulations (Directive 92/27/CEE) and Spanish legislation (Royal Decree 2.236/93, December 17) establish norms for labeling and package inserts for medicines used by human beings and define the sections to be included. Section 4.5 refers specifically to the interactions with other drugs, including alcohol. Therefore, the package inserts and Summary of Product Characteristics must provide information on the possible side effects of these substances as well as their possible interactions with others, including alcohol. In Spain, warning is given for all benzodiazepines in regard to their interactions with alcohol. But, apart from this information in the package inserts, it is very important for a physician prescribing a benzodiazepine to ask the patient about his or her habits relating to alcohol consumption and to inform and warn the patient of the possible risks when taking the benzodiazepine together with alcohol.

In accordance with the Spanish regulation, benzodiazepines must be prescribed by a physician, but there is no specific regulation for benzodiazepine prescription. A stricter and specific regulation regarding benzodiazepine prescription has been introduced in other countries (Weintraub et al., 1991), with a view to encouraging more rational prescription of these drugs.

The beneficial effects of benzodiazepine treatment for certain disorders (anxiety disorder, panic disorder, sleep disorder) have been clearly shown. Any benzodiazepine prescription should be preceded by careful diagnostic evaluation and consideration of the potential risks and benefits of alternative treatment options, mainly if there is a history of alcohol or other drug abuse (Posternak \& Mueller, 2001). Thus, appropriate education is necessary for both the patient and the physician, perhaps formalized in practice guidelines, instead of specific regulations that can restrict clinical judgment and lead to less desirable alternatives (Glass, 1991).

Nevertheless, it is essential to research prescription patterns and how benzodiazepines are taken in Spain to provide guidelines for regulatory decisions, with a view to implementing a more appropriate and rational use of such drugs in the future (Del Río \& Alvarez, 1996; Rayón et al., 1996).

\section{Acknowledgments}

We thank the Ministerio de Sanidad y Consumo for providing us with the 1997 Spanish National Household Health Survey computerized database. Support for this study was provided by the National Plan on Drugs (Delegación del Gobierno para el Plan Nacional sobre Drogas), Home Office (Ministerio del Interior), Madrid, Spain, as well as by the Consejería de Sanidad y Bienestar Social, Junta de Castilla y León, Valladolid, Spain.

\section{References}

Barbone, F., McMahon, A. D., Davey, P. G., Morris, A. D., Reid, I. C., McDevitt, D. G., \& MacDonald, T. M. (1998). Association of roadtraffic accidents with benzodiazepine use. Lancet 352, 1331-1336.

Del Río, C., Prada, C., \& Alvarez, F. J. (1995). Beverage effects on patterns of alcohol consumption. Alcohol Clin Exp Res 19, 1583-1586.

Del Río, M. C., \& Alvarez, F. J. (1996). How benzodiazepines are prescribed in a primary health care setting in Spain. Therapie 51, 185-189.

Del Río, M. C., Prada, C., \& Alvarez, F. J. (1996). The use of medication and alcohol among the Spanish population. Br J Clin Pharmacol 41, $253-255$.

Glass, R. M. (1991). Benzodiazepine prescription regulation: autonomy and outcome (Editorial). JAMA 266, 2431-2433. 
Gutierrez-Lobos, K., Frohlich, S., Quiner, S., Haring, C., \& Barnas, C. (2001). Prescription patterns and quality of information provided for consumers of benzodiazepines. Acta Med Austriaca 28, 56-59.

Harris, R. A., Mihic, S. J., \& Valenzuela, C. F. (1998). Alcohol and benzodiazepines: recent mechanistic studies. Drug Alcohol Depend 51, $155-164$.

Joukamaa, M., Sohlman, B., \& Lehtinen, V. (1995). The prescription of psychotropic drugs in primary health care. Acta Psychiatr Scand 92, $359-364$.

Lekka, N. P., Paschalis, C., \& Beratis, S. (1997). Nicotine, caffeine and alcohol use in high- and low-dose benzodiazepine users. Drug Alcohol Depend 45, 207-212.

Magrini, N., Vaccheri, A., Parma, E., D’Alessandro, R., Bottoni, A., Occhionero, M., \& Montanaro, N. (1996). Use of benzodiazepines in the Italian general population: prevalence, pattern of use and risk factors for use. Eur J Clin Pharmacol 50, 19-25.

Ministerio de Sanidad y Consumo (2000). Encuesta Nacional de Salud 1997. Madrid: Ministerio de Sanidad y Consumo.

Neutel, I. (1998). Benzodiazepine-related traffic accidents in young and elderly drivers. Hum Psychopharmacol Clin Exp 13, 115-123.

Ohayon, M. M., Caulet, M., Priest, R. G., \& Guilleminault, C. (1998). Psychotropic medication consumption patterns in the UK general population. J Clin Epidemiol 51, 273-283.

Posternak, M. A., \& Mueller, T. I. (2001). Assessing the risks and benefits of benzodiazepines for anxiety disorders in patients with a history of substance abuse or dependence. Am J Addict 10, 48-68.
Rayón, P., Serrano-Castro, M., del Barrio, H., Alvarez, C., Montero, D., Madurga, M., Palop, R., \& DeAbajo, F. J. (1996). Hypnotic drug use in Spain: a cross-sectional study based on a network of community pharmacies. Spanish Group for the Study of Hypnotic Drug Utilization. Ann Pharmacother 30, 1092-1100.

Rodríguez-Martos, A., Gual, A., \& Llopis, J. J. (1999). La "unidad de bebida estandar" como registro simplificado del consumo de bebidas alcohólicas y su determinación en España. Med Clin 112, 446-450.

Simon, G. E., VonKorff, M., Barlow, W., Pabiniak, C., \& Wagner, E. (1996). Predictors of chronic benzodiazepine use in a health maintenance organization sample. J Clin Epidemiol 49, 1067-1073.

Tanaka, E., \& Misawa, S. (1998). Pharmacokinetic interactions between acute alcohol ingestion and single doses of benzodiazepines, and tricyclic and tetracyclic antidepressants: an update. J Clin Pharm Ther 23, $331-336$.

Tiller, J. W. G. (1994). Reducing the use of benzodiazepines in general practice. $B M J 309,3-4$.

van der Waals, F. W., Mohrs, J., \& Foets, M. (1993). Sex differences among recipients of benzodiazepines in Dutch general practice. BMJ 307, $363-366$.

van Hulten, R., Leufkens, H. G., \& Bakker, A. (1998). Usage patterns of benzodiazepines in a Dutch community: a 10-year follow-up. Pharm World Sci 20, 78-82.

Weintraub, M., Singh, S., Byme, L., Maharaj, K., \& Guttmacher, L. (1991). Consequences of the 1989 New York State triplicate benzodiazepine prescription regulations. JAMA 266, 2392-2397. 